\title{
EL CALIGRAMA DEL LIBER SANCTI ANDREAE DE CASTELLO
}

\author{
Fidel Pascua Vílchez
}

Submetido em 17 de maio de 2019.

Aceito para publicação em 16 de julho de 2019.

Cadernos do IL, Porto Alegre, n. ${ }^{\circ}$ 59, outubro. p. 370-385.

\section{POLÍTICA DE DIREITO AUTORAL}

Autores que publicam nesta revista concordam com os seguintes termos:

(a) Os autores mantêm os direitos autorais e concedem à revista o direito de primeira publicação, com o trabalho simultaneamente licenciado sob a Creative Commons Attribution License, permitindo o compartilhamento do trabalho com reconhecimento da autoria do trabalho e publicação inicial nesta revista.

(b) Os autores têm autorização para assumir contratos adicionais separadamente, para distribuição não exclusiva da versão do trabalho publicada nesta revista (ex.: publicar em repositório institucional ou como capítulo de livro), com reconhecimento de autoria e publicação inicial nesta revista.

(c) Os autores têm permissão e são estimulados a publicar e distribuir seu trabalho online (ex.: em repositórios institucionais ou na sua página pessoal) a qualquer ponto antes ou durante o processo editorial, já que isso pode gerar alterações produtivas, bem como aumentar o impacto e a citação do trabalho publicado.

(d) Os autores estão conscientes de que a revista não se responsabiliza pela solicitação ou pelo pagamento de direitos autorais referentes às imagens incorporadas ao artigo. A obtenção de autorização para a publicação de imagens, de autoria do próprio autor do artigo ou de terceiros, é de responsabilidade do autor. Por esta razão, para todos os artigos que contenham imagens, o autor deve ter uma autorização do uso da imagem, sem qualquer ônus financeiro para os Cadernos do IL.

\section{POLÍTICA DE ACESSO LIVRE}

Esta revista oferece acesso livre imediato ao seu conteúdo, seguindo o princípio de que disponibilizar gratuitamente o conhecimento científico ao público proporciona sua democratização.

http://seer.ufrgs.br/cadernosdoil/index

Terça-feira, 29 de outubro de 2019. 


\title{
EL CALIGRAMA DEL LIBER SANCTI ANDREAE DE CASTELLO
}

\author{
THE CALLIGRAM OF LIBER SANCTI ANDREAE DE \\ CASTELLO
}

\author{
O CALIGRAMA DO LIBER SANCTI ANDREAE DE \\ CASTELLO
}

Fidel Pascua Vílchez*

\begin{abstract}
RESUMEN: análisis, transcripción y traducción del folio 1-verso del manuscrito Ms528 de la Bibliothèque Municipale de Cambrai (Francia), un códice inédito del siglo XII. Con base en el propio manuscrito, en Sánchez Prieto (2015) y en Godoi (2015), entre otros, analizamos su estructura, su contenido y su mensaje, ofreciendo, además, la transcripción completa a caracteres en fuente Times New Roman y su traducción. Concluimos que se trata de un tipo de escritura dedálica que comparte características de la escritura acróstica, teléstica y mesóstica; el folio no formaba parte inicial del códice; la estructura del caligrama es simétrica; contiene un error en la línea 38; el contenido es un canto de alabanza a Cristo, desde su nacimiento hasta la Resurrección.
\end{abstract}

PALABRAS CLAVE: escritura dedálica; Ms528 de Cambrai; manuscrito iluminado.

ABSTRACT: analysis, transcription and translation of the manuscript Ms528 folio 1-verso of Bibliothèque Municipale de Cambrai (France), an unpublished medieval codex of the $12^{\text {th }}$ century. Based on the manuscript itself, on Sánchez Prieto (2015), and on Godoi (2015), among others, we analyse its estructure, its content and message, while also providing the complete transcription into Times New Roman characters and its translation. We conclude that the calligram is a daedalian writing, sharing acrostical, telestical and mesostical writing features; initially, the folio wasn't part of the whole codex; the calligram structure is simetrical; it includes a mistake in line 38; the content is a song of praise to Christ, from his birth until the Resurrection.

KEYWORDS: daedalian writing; Ms528 of Cambrai; illuminated manuscript.

RESUMO: análise, transcrição e tradução do fólio 1-verso do manuscrito Ms528 da Bibliothèque Municipale de Cambrai (França), um códice inédito do século XII. Com base no próprio manuscrito, em Sánchez Prieto (2015) e em Godoi (2015), entre outros, analisamos sua estrutura, seu conteúdo e sua mensagem, oferecendo também a transcrição completa a caracteres Times New Roman e sua tradução. Concluímos que se trata de um tipo de escrita dedálica, compartilhando caraterísticas da escrita acróstica, teléstica e mesóstica; inicialmente, o fólio não fazia parte do códice; a estrutura do caligrama é simétrica; este contém um erro na linha 38; o conteúdo é um canto de louvor a Cristo, desde seu nascimento até a Resurreção.

PALAVRAS-CHAVE: escrita dedálica; Ms528 de Cambrai; manuscrito iluminado.

\section{Introducción}

\footnotetext{
* Profesor en la Universidad Federal de la Integración Latinoamericana (UNILA), Doctor en Estudios del Lenguaje por la Universidade Estadual de Londrina (UEL), e-mail: fidel.vilchez@unila.edu.br.
} 
El Liber sancti Andreae de castello es un códice iluminado inédito del siglo XII, depositado en la Bibliothèque Municipale de Cambrai (Francia) y catalogado como Manuscrit Ms528, con el título de Homiliarium. Según la ficha de la biblioteca, está constituido por 274 folios de pergamino encuadernados en cuero, sus dimensiones son 445x338mm y está escrito íntegramente en latín.

Este manuscrito está digitalizado íntegramente mediante escáner, en escala de grises y disponible en Internet, a través de la página web de libre acceso $B V M M$ Bibliotèque Virtuelle des Manuscrits Médiévaux <http://bvmm.irht.cnrs.fr/>. Por su parte, todas sus iluminaciones están digitalizadas y disponibles en color en el mismo site y también en la página web Enluminures, dependiente del Ministère de la Culture de Francia: 〈http://www.enluminures.culture.fr/>, también de libre acceso, aunque su uso está sujeto a derechos de autor. Por ese motivo, para evitar cualquier conflicto con los propietarios de los derechos de las imágenes, en lugar de descargarlas e incorporarlas al trabajo, remitimos al lector a sus respectivos enlaces web (Figura 1; Figura 2) y ofrecemos una transcripción de esta, formatada en Microsoft Word (Anexo).

Fuente 1: Enluminures.

$<$ Link a la imagen $>$

Figura 1: Folio 1-verso del Liber sancti Andreae de castello (f001v).

Fuente 2: BVMM Bibliothèque Virtuelle des Manuscrits Médiévaux.

$<$ Link2 a la imagen $>$.

Figura 2: Folio 1-verso del Liber sancti Andreae de castello (f001v).

El manuscrito debe su nombre al título que el último de los copistas le asignó a su conclusión en el verso del último folio, liber sancti Andree de castello, en una mezcla de latín y francés medieval.

El códice fue elaborado en la Abbaye de Saint-André du Cateau (Abbatia Sancti Andreae de Castello en latín; de ahí también el nombre del códice), una abadía benedictina fundada en el siglo XI, situada en la actual comuna francesa de Le CateauCambrésis, a veinticinco quilómetros de la ciudad de Cambrai, en el noreste de Francia. Según Godoi (2014, p. 430), la abadía fue consagrada por Gerard I, Obispo de Cambrai, alrededor del año 1020, y en el año 1048 la confirmó Henrique III, emperador del Sacro Imperio Romano Germánico.

La abadía sufrió diversas vicisitudes a lo largo de los siglos. Su acervo pasó a la Bibliotheca Sancti Sepulchri Camerai (Cambrai) y hoy está depositado en la Bibliothèque Municipale de Cambrai, incluido el Ms528.

El folio 1-verso del manuscrito contiene un caligrama (Figuras 1 y 2) que destaca por su belleza y complejidad. Sirve, además, de decoración inicial del mismo en su encuadernación actual, aunque, en un principio, no formaba parte de este. Fue incluido después en una encuadernación posterior. Esto se demuestra porque los demás folios están ordenados en números romanos en la parte superior central, pero este que contiene el caligrama en el verso y la imagen de un copista en el recto, no sigue esa misma numeración romana.

Sin embargo, en el folio siguiente, en el que está plasmada la imagen de un hermoso pantocrátor o Cristo Majestad, escoltado por las figuras del apóstol san Andrés (el patronímico de la abadía), y de santa Maxelendis, una mártir de Cambrai, completada con la figura de un monje llamado Rainerus postrado en señal de súplica, se puede leer la anotación de un catalogador o bibliotecario denominado a sí mismo como 
Magister Johannes Folksperg, quien en el año 1793 revisó el manuscrito y le añadió a los folios, en su parte superior derecha, una nueva numeración en caracteres arábigos, incluyendo ya el folio del caligrama.

El códice, sin duda, tuvo más de una encuadernación a lo largo de los siglos, porque se percibe que los folios han sido recortados en la parte superior para adaptarlos a una medida menor, con perjuicio de algunas iniciales decoradas que han sufrido la mutilación de alguno de sus elementos.

Dado su carácter inédito, consideramos oportuno su análisis, transcripción y traducción, con el objeto de darlo a conocer, siendo este uno de los varios trabajos que surgirán a partir del Ms528 de Cambrai. Todos esos trabajos tendrán como fin último la publicación del contenido íntegro del manuscrito en un futuro a medio plazo.

\section{Clasificación codicológica del tipo de texto}

Este tipo de textos ornamentales al principio del manuscrito es uno de los más frecuentes métodos que se utilizaban en la época medieval para la decoración inicial de los códices. Según Sánchez Prieto (2015, p. 1), existen cuatro procedimientos básicos destinados a ese fin: las letras distintivas, las escrituras realzadas, los caligramas y la escritura dedálica. De todos ellos, el texto del folio 1-verso del Ms528 de Cambrai comparte características del primero, tercero y cuarto tipos:

Por un lado, se le puede considerar un caligrama, porque el texto, en su conjunto, ha sido dispuesto de manera que sus líneas de escritura forman una imagen; en este caso, la de una reja o parrilla que representa la forma del tablero del juego de las Tres en Línea, de manera que el lector se ve en la necesidad de hacer una lectura analítico-discursiva y sintético-ideográfica. Existen precedentes de este tipo de texto decorativo desde la época helenística.

Abundando en esta idea del juego de las Tres en Línea, nótese cómo en las posiciones del texto equivalentes a los puntos donde se pueden colocar las fichas, piedras, $\mathrm{X}$ o $\mathrm{O}$, etc., de dos tipos diferentes, correspondiendo un tipo a cada jugador, están situadas una letra A mayúscula o una M mayúscula (Figura 3). En este caso, las emes han conseguido alinearse en las dos diagonales del tablero. Esta disposición de las emes y aes, que se destaca por su tamaño en relación a las demás y también por su ubicación estratégica, para causar impacto en el lector, nos remite al concepto de letra distintiva:

Aquellos caracteres alfabéticos que intencionadamente sobresalen del texto por su módulo, su forma o su ornamentación, con la finalidad de producir algún impacto en el lector y establecer así una jerarquía gráfica en la página (SÁNCHEZ PRIETO, 2015, p. 1-2) 
Fuente: ELABORACIÓN NUESTRA, 2019.

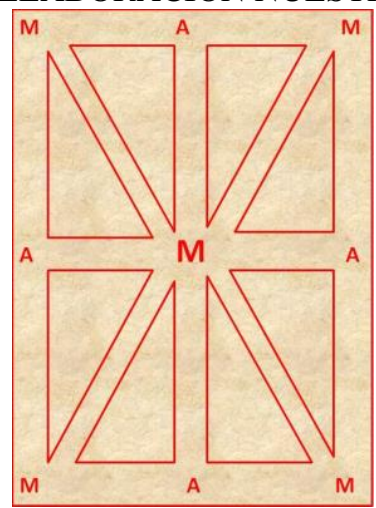

Figura 3: Juego de las Tres en línea en el caligrama del Ms528 de Cambrai.

Por otro lado, el texto presenta también características de la escritura dedálica, un tipo de escritura que busca la ingeniosidad y la estética. Sánchez Prieto (2015, p.8) distingue dentro de esta categoría entre laberintos, acrósticos, telésticos, monogramas y anagramas. Para el texto del manuscrito objeto de análisis en este trabajo, resulta pertinente atender a la definición que la autora ofrece de los modelos acróstico y teléstico:

Otras modalidades de escrituras dedálicas son el acróstico y el teléstico. En el acróstico las primeras letras de cada línea producen un mensaje paralelo al texto principal, mientras que en el teléstico son las últimas letras las que transmiten el mensaje (SÁNCHEZ PRIETO, 2015, p. 9)

Evidentemente, el texto en foco participa de ambas definiciones, a las que hay que añadirle también el concepto de "mesóstico"; es decir, aquel texto cuyas letras situadas en el centro transmiten un mensaje, conjuntando así los elementos ornamentales con los efectos interpretativos, el significante con el significado, produciendo en el lector una sensación lúdica y placentera.

El caligrama del Liber sancti Andreae de castello puede considerarse un acróstico, ya que las 37 iniciales de cada una de las 37 líneas horizontales, leídas de arriba abajo, producen un mensaje paralelo al texto principal: MANSIT APVD PATREM GRATAM LEGIT SIBI MATREM ("Permaneció junto al Padre; escogió para sí una grata Madre", - traducción nuestra).

Al mismo tiempo, se le puede considerar también un teléstico, porque las últimas letras de cada una de las 37 líneas, leídas de arriba abajo, transmiten otro mensaje paralelo: MENTE VEL ORE SACRAM LAVDEMVS AMANDO MARIAM ("Mentalmente o de palabra alabemos, amando, a la sagrada María", - traducción nuestra).

Entra, además, dentro de la categoría de los mesósticos, porque las letras centrales de cada una de las 37 líneas horizontales; es decir, las letras número diecinueve de cada línea, leídas de arriba abajo, transmiten otro mensaje paralelo: AETHERE GLORIFICA IAM PSALLIT VOCE CATERVA ("Un coro en el cielo canta ya con su gloriosa voz", - traducción nuestra).

Son también escrituras dedálicas mesósticas las dos diagonales que van de extremo a extremo del caligrama, pasando por la gran eme mayúscula central, leídas de arriba abajo. La primera de ellas, parte de la eme situada en el extremo superior 
izquierdo, hasta llegar a la eme del extremo inferior derecho, transmitiendo un mensaje en primera persona del singular, en el que el autor se refiere a sí mismo y al fin que se propone con el dibujo del caligrama: METRI PINGO MODVM PROMENS PRAECONIA LAVDVM ("Dibujo un modelo de medida que expresa proclamas de alabanzas", - traducción nuestra).

La segunda diagonal parte del extremo superior derecho y va hasta el extremo inferior izquierdo, pasando por la eme central, ofreciendo el siguiente mensaje: MIRENTVR DOMINVM CLAMENT SIMVL OMNIA NATVM ("Que todas las cosas admiren al Señor; que proclamen al unísono que ha nacido", - traducción nuestra).

Además de las tres líneas verticales de 37 letras que forman escrituras dedálicas acrósticas, telésticas y mesósticas, destacadas en mayúsculas y en color rojo, junto a las dos diagonales, también escrituras mesósticas, resaltan por su realce en el texto las líneas horizontales superior, central e inferior, si bien a estas no se las puede incluir en ninguna de las categorías mencionadas, porque su lectura se hace de izquierda a derecha, en el sentido normal de la lectura en latín.

Otro tipo de escritura decorativa de la que participa el caligrama es la denominada en Codicología como "Pie de lámpara" o Cul-de-lampe, consistente en la adición o sustracción de una o varias letras, de manera secuencial, a medida que se lee el texto de arriba abajo o de abajo arriba (Figura 4).

El modelo más común de caligrama en forma de pie de lámpara es aquel que está centralizado y, a medida que las líneas van disminuyendo su número de letras, el tamaño de la línea va disminuyendo también de manera simétrica en relación al eje central, dibujando, de ese modo, la figura de un triángulo invertido.

Sin embargo, la figura que dibujan las disposiciones en pie de lámpara de los triángulos que conforman el caligrama del Ms528 es la de triángulos rectángulos, dispuestos de hasta cuatro maneras diferentes: con el cateto menor como base y la hipotenusa a la derecha; con el cateto menor como base y la hipotenusa a la izquierda; cada uno de estos dos modelos de manera invertida, con el vértice de la hipotenusa abajo (Cf. Figura 7).

Fuente: ELABORACIÓN NUESTRA, 2019.

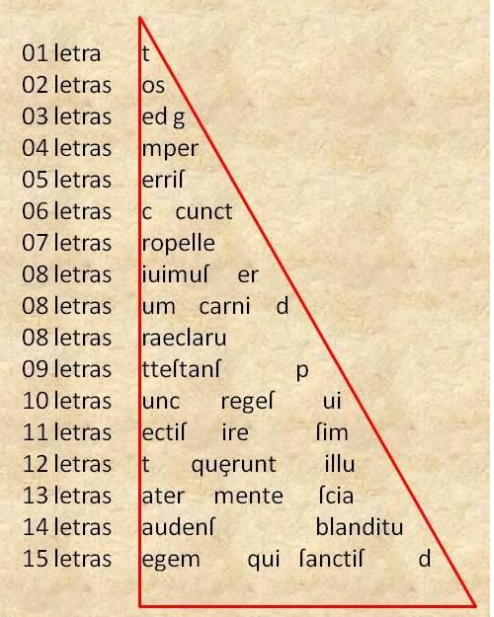

Figura 4: Organización del texto del caligrama en pie de lámpara inverso. 


\section{Organización externa e interna del caligrama}

El caligrama está dispuesto en 37 líneas horizontales, de 37 letras cada una, salvo en las líneas diez y veintiocho (la línea veintiocho es la diez contando de abajo arriba). Estas dos líneas tienen 35 letras cada una. Al mismo tiempo, las tres líneas verticales destacadas en rojo también están formadas por 37 letras, al igual que las dos líneas diagonales en rojo que pasan por el centro.

De esta forma, el texto en su conjunto está organizado de manera simétrica, con una excepción: la fila diecisiete, comenzando a contar por la fila superior, tiene 38 letras.

Hay nueve letras en el caligrama que destacan por su tamaño, por su disposición en el texto y por el número de líneas horizontales, verticales y/o diagonales de las que forman parte, a partir de las cuales está estructurado todo el conjunto. Son la gran eme central, las cuatro emes de las esquinas y las cuatro aes situadas en el centro de las líneas exteriores:

La gran eme central es la clave o piedra angular sobre la que se estructura el caligrama, pues está ubicada en el centro del mismo y forma parte de cuatro líneas principales destacadas en mayúsculas: la horizontal central, la vertical central y las dos diagonales.

Además, es diferente a las otras cuatro emes mayúsculas principales, pues está dibujada no a partir de cuatro trazos rectos, sino de un gran eje central vertical, en forma de i mayúscula; hacia su derecha, se prolonga un trazo semicircular, rematado con otro recto oblicuo, de modo que, junto al trazo vertical, conforma una erre mayúscula; a su vez y de manera simétrica e inversa, se prolonga otro trazo igual hacia la izquierda del trazo vertical en forma de $\mathrm{i}$, de modo que conforma una letra a mayúscula. De esa forma, en la gran eme central están representadas todas las letras de la palabra "María".

En orden de importancia en la disposición del conjunto, siguen a la gran eme central las otras cuatro emes de las esquinas, las cuales forman parte del comienzo o final de tres líneas principales: una horizontal, una vertical y una diagonal. Además, están alineadas con la eme central, dispuestas de forma ganadora en el juego de las Tres en Línea y dibujando, al mismo tiempo, la cruz de san Andrés o crux decussata, en honor al martirio del patrono de la abadía.

En tercer lugar en importancia, fueron dispuestas en el texto las cuatro aes centrales de las líneas exteriores, en la intersección de dos líneas principales: una vertical y otra horizontal, en forma de cruz griega o crux immissa quadrata.

Después, la décima letra de las diagonales y de la vertical central, tanto de arriba abajo como de abajo arriba, es una $\mathrm{O}$ mayúscula, de forma que están alineadas en línea recta entre sí, en el centro de los dos semiplanos del folio (Figura 5).

A partir del esquema básico representado en la Figura 5, se fueron completando primero las líneas horizontal central, superior e inferior; las verticales izquierda, central y derecha; las dos diagonales y, finalmente, cada una de las 34 líneas horizontales restantes.

Desde la letra eme mayúscula central hasta cualquiera de los ocho extremos hay diecinueve letras, contando la propia eme. A su vez, desde cualquier letra de los bordes exteriores hasta la columna central también hay diecinueve letras, de manera que hay dieciocho letras a la izquierda y dieciocho letras a la derecha de cada letra de la columna central. Sin embargo, esta regla no se cumple en la línea diez ni en la veintiocho (línea diez contando de abajo arriba), tanto si se cuenta de arriba abajo como si se cuenta de 
abajo arriba. En ambas líneas hay solamente diecisiete letras a ambos lados: es una disposición simétrica.

Otro detalle que llama la atención es que, en las dos filas de 35 letras, que corresponden a las décimas filas si se cuentan desde arriba y desde abajo, hay tres letras oes mayúsculas en las tres líneas interiores principales: las dos diagonales y la columna central:

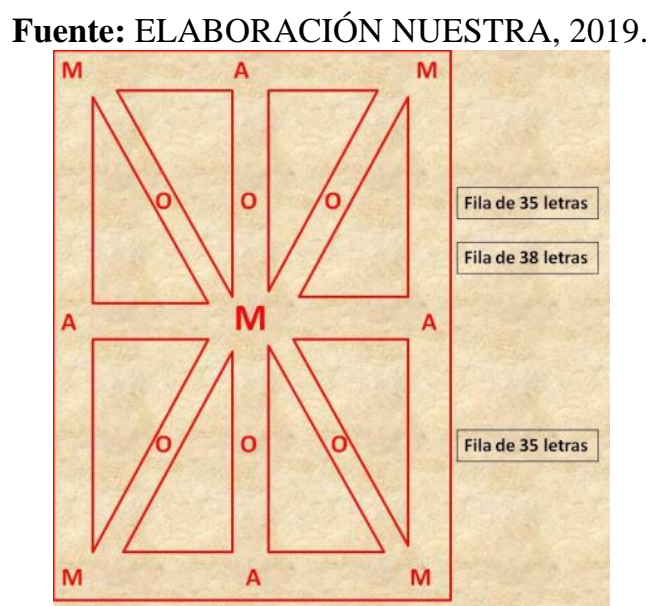

Figura 5: Filas del caligrama que no tienen 37 letras.

Las ocho líneas principales del caligrama que confluyen en la gran eme central, todas formadas por mayúsculas en color rojo, tienen, por un lado, valor independiente, porque en sí mismas transmiten un mensaje. Por otro lado, forman parte del conjunto del texto, que se lee de manera normal, de izquierda a derecha, en sus 37 líneas.

Para completar su sentido, entre las ocho líneas principales hay colocados, de manera simétrica, ocho triángulos rectángulos (Figura 6), que resultan de la división del plano en cuatro rectángulos mediante las líneas centrales horizontal y vertical, y, a su vez, de la división de estos cuatro rectángulos en ocho triángulos mediante las dos líneas diagonales:

Fuente: ELABORACIÓN NUESTRA, 2019.

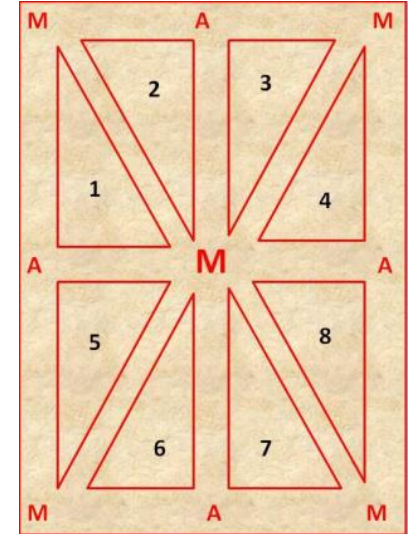

Figura 6: División en ocho triángulos del caligrama. 
La composición interna de estos triángulos sorprende también por su complejidad. Forman en sí mismos caligramas independientes, elaborados en función de la adición o sustracción de una letra en cada línea, en forma de pie de lámpara, como adelantamos en la sección anterior.

En los triángulos con el ángulo recto en su base, identificados en la Figura 6 como 1, 4, 6 y 7, la primera línea incluye una letra; la segunda, dos; la tercera, tres, y así hasta llegar a las líneas ocho, nueve y diez, que incluyen ocho letras cada una; a partir de ahí, el número de letras se sigue incrementando de una en una, hasta llegar a la línea de la base del triángulo, que tiene quince letras.

Por su parte, los triángulos que no tienen el ángulo recto en su base, señalados en la Figura 6 como 2, 3, 5 y 8, están dispuestos de manera inversa: la línea superior incluye quince letras; la siguiente, catorce; la siguiente, trece, y así hasta la octava línea, que tiene ocho letras; la novena tiene siete; la décima, ocho; la undécima, siete otra vez; a partir de ahí, el número de letras continua disminuyendo, hasta llegar a una sola (Figura 7).

Sucede, además, que los triángulos están relacionados entre sí de dos en dos hasta la línea vertical central, y de cuatro en cuatro de un extremo a otro de la línea, porque el conjunto de letras que incluye cada línea en ellos se suma a la de los demás, para que así cada línea tenga 37 letras (con la excepción de las líneas diez y veintiocho).

Fuente: ELABORACIÓN NUESTRA, 2019.

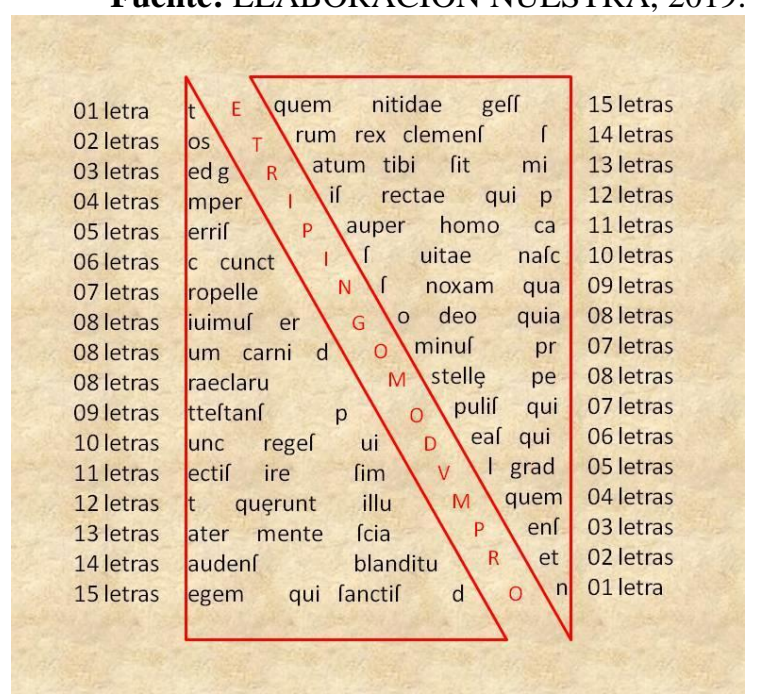

Figura 7: Estructura de los triángulos del caligrama (Ej.: triángulos 1 y 2).

De esta manera, la novena, undécima, vigesimoséptima y vigesimonovena líneas del caligrama tienen todas ocho letras en cada uno de sus cuatro triángulos.

Otra característica que se cumple es la relación de pares de números de letras en los triángulos que forman el caligrama.

Considerando que cada línea abarca cuatro triángulos, exceptuando las líneas verticales exteriores, la vertical central y las diagonales, nos queda la siguiente relación de pares de números de letras, atendiendo a la estructura de las Figuras 5 y 6 : 
Líneas del caligrama que forman los triángulos 1, 2, 3 y 4 de la Figura 6 y relación de pares de números que incluyen:

Línea 2: 1-15-15-1; línea 3: 2-14-14-2; línea 4: 3-13-13-3; línea 5: 4-12-12-4; línea 6: 5-11-11-5; línea 7: 6-10-10-6; línea 8: 7-9-9-7; línea 9: 8-8-8-8; línea 10: 8-7-78; línea 11: 8-8-8-8; línea 12: 9-7-7-9; línea 13: 10-6-6-10; línea 14: 11-5-5-11; línea 15: 12-4-4-12; línea 16: 13-3-3-13; línea 17: 14-2-2-15 (aquí está el único error del caligrama); línea 18: 15-1-1-15.

Líneas del caligrama que forman los triángulos 5, 6, 7 y 8 de la Figura 6 y relación de pares de números que incluyen:

Línea 20: 15-1-1-15; línea 21: 14-2-2-14; línea 22: 13-3-3-13; línea 23: 12-4-412; línea 24: 11-5-5-11; línea 25: 10-6-6-10; línea 26: 9-7-7-9; línea 27: 8-8-8-8; línea 28: 8-7-7-8; línea 29: 8-8-8-8; línea 30: 7-9-9-7; línea 31: 6-10-10-6; línea 32: 5-11-115; línea 33: 4-12-12-4; línea 34: 3-13-13-3; línea 35: 2-14-14-2; línea 36: 1-15-15-1.

\section{El error de la línea diecisiete}

Por lo visto hasta aquí, se puede determinar que el autor del caligrama se propuso elaborar una composición de treinta y siete líneas horizontales, de 37 letras cada una. De estas 37 letras, cinco corresponden a las mayúsculas destacadas en las verticales izquierda, central y derecha, junto a las mayúsculas de las dos diagonales; las otras treinta y dos letras de cada línea están contenidas en cuatro triángulos, con la disposición explicada en la sección anterior.

Sin embargo, hay una línea, la diecisiete, que incluye una letra más - esto es, tiene 38 letras. Según el análisis numérico realizado, el error por adición está en el último triángulo, señalado en la Figura 6 con el número 4. Esa línea, en ese triángulo, debería incluir catorce letras, pero incluye quince.

La línea diecisiete contiene el siguiente mensaje, referido a la Virgen María:

"Gaudens blanditur et in ulnis gestat alendum" ("Acaricia y lleva gozosa en los brazos al que ha de alimentar" - traducción nuestra).

La disposición del mensaje en el texto, según la distribución ya explicada, es la siguiente (Tabla 1):

Tabla 1: Disposición de la línea diecisiete

\begin{tabular}{|c|c|c|c|c|c|c|c|c|c|}
\hline Posición & $\mathrm{I}$ & $\Delta 1$ & $\mathrm{I}$ & $\Delta 2$ & $\mathrm{I}$ & $\Delta 3$ & $/$ & $\Delta 4$ & $\mathrm{I}$ \\
\hline Texto & $\mathrm{G}$ & auden blanditu & $\mathrm{R}$ & et & $\mathrm{I}$ & $\mathrm{nu}$ & $\mathrm{L}$ & nif geftat alendu & $\mathrm{M}$ \\
\hline Letras & 1 & 14 & 1 & 2 & 1 & 2 & 1 & 15 & 1 \\
\hline
\end{tabular}

Fuente: elaboración nuestra.

Es llamativo que el autor no haya querido resolver el problema del triángulo cuatro, porque si ha sido capaz de componer en su totalidad el caligrama, con esa enorme dificultad que comporta, no parece demasiado complicado, a priori, encontrar una palabra con una letra menos que sustituya a gestat o a alendum.

Por ejemplo, el verbo gesto, -as, -are (frecuentativo de gero), significa "llevar consigo", "transportar". Una alternativa habría podido ser tenet, de cinco letras, que 
significa "sostener", "sujetar", sin que el sentido de la oración hubiese cambiado sustancialmente: "Acaricia y sostiene gozosa en los brazos al que ha de alimentar".

La otra opción posible habría sido buscar una palabra de seis letras que hubiese sustituido a alendum, aunque no hubiese tenido el mismo significado de "alimentar" o "nutrir". Por ejemplo, la palabra filium "hijo" tiene seis letras, termina también en eme y da sentido pleno a la oración: "Acaricia y lleva gozosa a su hijo en brazos".

Incluso habría cabido la posibilidad de declinar la palabra ulna, -ae "antebrazo", que en el texto aparece en su forma de ablativo plural ulnis, abarcando el triángulo 3, la diagonal derecha y el triángulo cuatro, en su forma de ablativo singular ulna, reduciendo, de ese modo, en una letra el triángulo sin apenas cambiar el sentido: "Acaricia y lleva gozosa en el brazo al que ha de alimentar".

Debe destacarse que el autor fue consciente del error en la fila diecisiete, porque todas las filas del caligrama, salvo esa, tienen en el extremo derecho una marca en forma de punto o de punto y coma como comprobación de que la distribución de las letras en la fila es la correcta (Cf. Figura 1 y 2; Anexo). Por ese motivo, se debe deducir que solo fue consciente del mismo al final y, por algún motivo desconocido, no quiso corregirlo raspando el pergamino con el rasorium y reescribirlo con alguna alternativa que cuadrase la línea al cien por ciento.

\section{El texto original en latín}

A continuación, se ofrece la transcripción del texto en latín del caligrama a caracteres tipográficos de la fuente Times New Roman, para facilitar su lectura. El original fue escrito en letra carolina del siglo XII, incluyendo algunas abreviaturas típicas de ese tipo de escritura, así como caracteres que no existen en español moderno. La transcripción literal del caligrama, con sus abreviaturas ${ }^{2}$ y caracteres especiales ${ }^{3}$ se puede ver en el Anexo.

Línea 1: Magnificando Deum psallat vox omnis in aevum

Línea 2: A te quem nitidae gesserunt claustra Mariae

Línea 3: Nostrum Rex clemens studeo deducare carmen

Línea 4: Sed gratum tibi sit, mihi ne tua munera desint

Línea 5: Imperiis rectae qui perspicit omnia normae

Línea 6: Terris pauper homo carnis sumpto fit amictu

Línea 7: Ac cunctis vitae nascens spem contulit in se

Línea 8: Propellens noxam qua gens male corruit exul

Línea 9: Vivimus ergo Deo quia lux redit addita mundo

Línea 10: Dum carni Dominus pro servis consociatur

Línea 11: Praeclarum stellae percurrit lumen in aethere

Línea 12: Attestans populis, quia natus sit Deus illis

Línea 13: Tunc reges videas qui fervent noscere signa

Línea 14: Rectis ire simul gradibus seu visibus illuc

Línea 15: Et quaerunt illum quem caelum stellaque fantur

Línea 16: Mater mente scia pensat recolens nova verba

Línea 17: Gaudens blanditur et in ulmis gestat alendum

\footnotetext{
${ }^{2} \mathrm{q} ;$ : abreviatura de-que.

${ }^{3}$ Ȩ: letra latina E mayúscula con cedilla. Abreviatura de $A E$ o $A e$; ȩ: letra latina e minúscula con cedilla. Abreviatura de $a e$; I: letra latina ese larga o "ese de gancho". Alterna en el texto con $s$.
} 
Línea 18: Regem qui sanctis donabat in aethere tribunal

Línea 19: Arce sedens supera Dominus descendit ad ima

Línea 20: Tempore quo verae resplendens carnis in usu

Línea 21: Auctor erat mundi, nam signa dabat nova David

Línea 22: Multos tunc sanctae suadens ad praemia vitae

Línea 23: Lege pia traxit stabilem reparando salutem

Línea 24: Et qui nostra simul vel summa regit dominatu

Línea 25: Gressu sic humili petit aegros ac vivat illos

Línea 26: Invalidos curat, levat ipse iacentia membra

Línea 27: Tunc caecus lucem, surdus quoque percipit aurem

Línea 28: Sed sermo non tanta potest exponere gesta

Línea 29: Ille quidem mutis cunctisque ferendo iuvamen

Línea 30: Blandus in orbe fuit, sed fari iam libet illud

Línea 31: In populis sacro quod cum fert dogmata verbo

Línea 32: Mortis ad exitium saevae dat plebs mala Iesum

Línea 33: Atque tenens poena velut agnum damnat acerba

Línea 34: Terra movebatur cruce Christi, sed renovatur

Línea 35: Rectos laetificat surgens, vult ipse videri

Línea 36: Et vivus monstrat latus et post vescitur una

Línea 37: Mirifice formam libravit ad aethera nostram

Vertical izquierda: Mansit apud Patrem, gratam legit sibi Matrem

Vertical central: Aethere glorifica iam psallit voce caterva

Vertical derecha: Mente vel ore sacram laudemus amando Mariam

Diagonal izquierda: Metri pingo modum promens praeconia laudum

Diagonal derecha: Mirentur Dominum, clament simul omnia natum

\section{La traducción al español}

Línea 1: Que cante toda voz para glorificar a Dios por siempre

Línea 2: ¡Ah! A ti, al que albergaron las entrañas de la radiante María

Línea 3: Me afano, Rey clemente, en componer mi poema

Línea 4: Pero espero que te sea grato, para que no me falten tus dádivas

Línea 5: El que observa todo en los dominios de la Ley correcta

Línea 6: En la tierra, asumiendo la apariencia carnal, se hace un hombre pobre

Línea 7: Y, al nacer, trae consigo una esperanza de vida para todos

Línea 8: Expulsando el delito con el que el pagano, proscrito, fracasó del todo

Línea 9: Así pues, vivimos por Dios, porque la luz regresó de vuelta al mundo

Línea 10: Mientras el Señor se encarna en pro de sus siervos

Línea 11: La luz brillante de una estrella recorre el firmamento

Línea 12: Atestiguando a los pueblos que les ha nacido Dios

Línea 13: Verías entonces a los Reyes Magos que ansían con fervor entender las señales

Línea 14: Ir allí con pasos rectos y, al mismo tiempo, mirando al firmamento

Línea 15: Y buscan al que anuncian el cielo y la estrella

Línea 16: La Madre, sabedora en sus mientes, piensa recordando la buena nueva

Línea 17: Acaricia gozosa y lleva en sus brazos al que ha de alimentar

Línea 18: Al Rey que premiaba a los santos en el tribunal del cielo 
Línea 19: El Rey que preside en la ciudad de las alturas descendió a las profundidades

Línea 20: En el tiempo en el que, resplandeciente en el uso de verdadera carne,

Línea 21: Era el Garante del mundo, pues daba nuevas señales de David

Línea 22: Persuadiendo entonces a muchos de los beneficios de una vida santa,

Línea 23: los atrajo con la ley pía, otorgando a cambio la segura salvación

Línea 24: Y el que, al mismo tiempo, se encarga de gobernar nuestra vida o las alturas,

Línea 25: Con paso humilde se acerca a los enfermos y les devuelve la salud,

Línea 26: Cura a los inválidos; Él mismo yergue los miembros postrados

Línea 27: Entonces, el ciego percibe la luz; el sordo también percibe el sonido

Línea 28: Pero este relato no es capaz de exponer tan grandes prodigios

Línea 29: Aquel, prestando ciertamente ayuda a los mudos y a todos

Línea 30: Fue tierno en este mundo, pero ya place decirlo:

Línea 31: Cuando con su santa palabra expone la Nueva Ley a los pueblos

Línea 32: La plebe perversa entrega a Jesús a la ruina de una muerte cruel

Línea 33: Y manteniéndole los despiadados tormentos, lo condena como a un Cordero

Línea 34: La tierra se conmovía con la cruz de Cristo, pero es renovada

Línea 35: Resucitando, lleva la alegría a los justos; Él mismo quiere ser visto

Línea 36: Y, vivo, muestra el costado y, después, se alimenta una vez

Línea 37: De modo admirable, equilibró en la balanza nuestra condición humana para que esta fuese al cielo

Vertical izquierda: Permaneció junto al Padre; escogió para sí una grata Madre

Vertical central: Un coro en el cielo canta ya con su gloriosa voz

Vertical derecha: Mentalmente o de palabra, alabemos amando a la sagrada María

Diagonal izquierda: Dibujo un modelo de medida que expresa proclamas de alabanza

Diagonal derecha: Que todas las cosas admiren al Señor; que proclamen al unísono que ha nacido

\section{Conclusiones}

El caligrama del Liber sancti Andreae de castello es un texto de enorme complejidad, máxime teniendo en cuenta que fue compuesto en una lengua diferente a la lengua materna del autor. Esta, dada la ubicación del monasterio en que fue escrito, una zona del noreste de Francia, limítrofe con Flandes y perteneciente en aquella época al Sacro Imperio Romano Germánico, debía de ser francés medieval, neerlandés o algún dialecto alemán. Quizá fuera fluente en más de una.

Por muy experto en la lengua latina que fuese el autor, la dificultad que comporta la producción escrita de un texto en lengua ajena, condicionado a la cuadratura del sentido de las líneas que se entrecruzan en diferentes direcciones, supuso, sin duda, un enorme desafío a su autor y resalta su mérito. Cualquiera que intente componer un texto similar en su propia lengua, se dará cuenta de la enorme dificultad que supone. Imagínese hacerlo en una lengua distinta. 
A esta dificultad intrínseca de componer un texto entrecruzado se le ha de sumar la de la escasez de la superficie de escritura. A priori, sorprende que el monje se haya apropiado de un folio de pergamino para un propósito tan superfluo como dibujar su imagen en el recto y un caligrama en el verso.

Para elaborar un caligrama de semejante complejidad, hay que escribir repetidas veces y comprobar que todos los sentidos en diferentes direcciones están correctos; sin embargo, no existe la posibilidad de borrar muchas veces, porque esto se hace mediante el rasorium, que raspa y va deteriorando la superficie. Además, el copista medieval disponía de un número muy limitado de folios de pergamino, y no para este tipo de artificios, precisamente. Piénsese que el códice contiene 274 folios de pergamino. Si consideramos que cada oveja produce 4 folios, nos da algo más de 68 ovejas.

Obviamente, el autor partió del esquema básico o plantilla del caligrama descrita en la Figura 5; después, escribió, por este orden: la línea horizontal central, la superior y la inferior; más tarde, las verticales izquierda, central y derecha; a continuación, las dos diagonales; finalmente, fue escribiendo las 34 líneas horizontales de arriba abajo.

Cada una de estas 34 líneas fue pensada previamente y, solamente después de comprobar que cuadraba el sentido y el número de letras a cada lado de las líneas principales, fue escrita sobre la superficie, evitando así el raspado innecesario del soporte de escritura. Pero esto no exime del cálculo repetido antes de pasarlo por escrito para evitar eventuales errores $y$, como consecuencia de ello, el raspado del pergamino y su deterioro.

El códice está escrito, pues, sobre superficie de pergamino, material escaso y valioso. El poco pergamino del que se disponía en el monasterio estaba destinado a la copia del Liber sancti Andreae de castello, un homiliario del que este folio no formaba parte originalmente. Esto se demuestra porque no está incluido en la primera numeración de las páginas que hicieron los copistas en época medieval, con números romanos en la parte central superior de los folios, sino en la segunda que estableció un tal Magister Johannes Folksperg en el año 1793, en números arábigos. A lo que parece, este actual folio 1 del códice fue incluido en una encuadernación posterior a la original.

Eventualmente, puede no ser una obra original, y tratarse de la copia de un modelo anterior, pero no se ofrecen datos sobre este asunto en el códice. En cualquier caso, se trata de un texto inédito, pues no consta en las principales colecciones de textos latinos, como Migne, Teubner, Loeb y Oxford, tampoco en los principales repositorios digitales de obras y autores cristianos, como Corpus corporum repositorum operum latinorum apud Universitatem Turicensem, de la Universidad de Zúrich, Perseus Digital Library, de la Universidad de Tufts, en Boston, o Documenta Catholica Omnia, el mayor archivo digital en Internet de las obras de autores cristianos antiguos y medievales editadas por Jacques Paul Migne entre 1844 y 1855.

Nuestra opinión, es que se trata de una obra original, que expresa la devoción del autor a Cristo y supone también un ejercicio de vanidad, reforzado por el hecho de que la imagen del autor está plasmada en el recto del folio.

Cabe preguntarse por qué el autor eligió un caligrama de 37 líneas con 37 letras cada una; es decir, por qué este número y no otro. Evidentemente, esta disposición del texto no fue casual, fue estructurado de esa forma con una determinada intención y, en ese sentido, al tratarse de un texto incluido en un homiliario, escrito por un fraile de una abadía benedictina, parece lo más lógico atribuir la causa a una motivación religiosa, vinculada a este número. Por ejemplo, 37 son los milagros atribuidos a Cristo en los Evangelios. 
Sin embargo, en nuestra opinión, parece más lógico pensar que la elección del número 37 tiene más que ver con cuestiones puramente geométricas. Se trata de un número impar que permite la disposición simétrica de las líneas a uno y otro lado de la línea central horizontal: dieciocho arriba y dieciocho abajo.

Igualmente, las 37 letras por línea obedecen a la misma distribución geométrica a un lado y otro de la línea central vertical: dieciocho a la izquierda y dieciocho a la derecha; y lo mismo con las dos diagonales: dieciocho letras antes de la eme central y dieciocho después. Esta idea queda reforzada por el mensaje de la diagonal izquierda: Metri pingo modum promens praeconia laudum ("Dibujo un modelo de medida que expresa proclamas de alabanza", - traducción nuestra), aludiendo tanto al caligrama como al fin que perseguía con este.

\section{REFERENCIAS}

BVMM BIBLIOTHÈQUE VIRTUELLE DES MANUSCRITS MÉDIÉVAUX. 7. Cambrai, Bibliothèque municipale 0528 (0487), $f$. Disponible en: https://bvmm.irht.cnrs.fr/consult/consult.php?VUE_ID=1712693. Acceso en: 13 mayo 2019.

DOCUMENTA CATHOLICA OMNIA. Migne Tabulinum. 2006. Disponible en: http://www.documentacatholicaomnia.eu/25_10_MPL.html. Acceso em: 15 mayo 2019.

GODOI, P. W. O copista de Cambrai: Rainerus e a representação do artista na Idade Média. Anais da XIX Semana de História VII Forum de Pós-Graduação em História e II Forum de Licenciatura em História Realizada - O profissional de História e seus desafios. Temática de ensino e pesquisa, Vol. 1, p. 587-598. 2015.

MINISTÈRE DE LA CULTURE. Enluminures. Cambrai-BM-Ms. $528 f 001$. Disponible en: http://www.enluminures.culture.fr/documentation/enlumine/fr/BM/cambrai_02301.htm. Acceso en: 13 mayo 2019.

SÁNCHEZ PRIETO, A. B. La decoración del códice. 2. La escritura como elemento decorativo. En: Academia.es. 2015. Disponible en: https://www.academia.edu/28844607/La_decoraci\%C3\%B3n_del_c\%C3\%B3dice._2._ La_escritura_convertida_en_elemento_decorativo. Acceso en: 13 mayo 2019. 
Anexo 1: Reproducción del caligrama

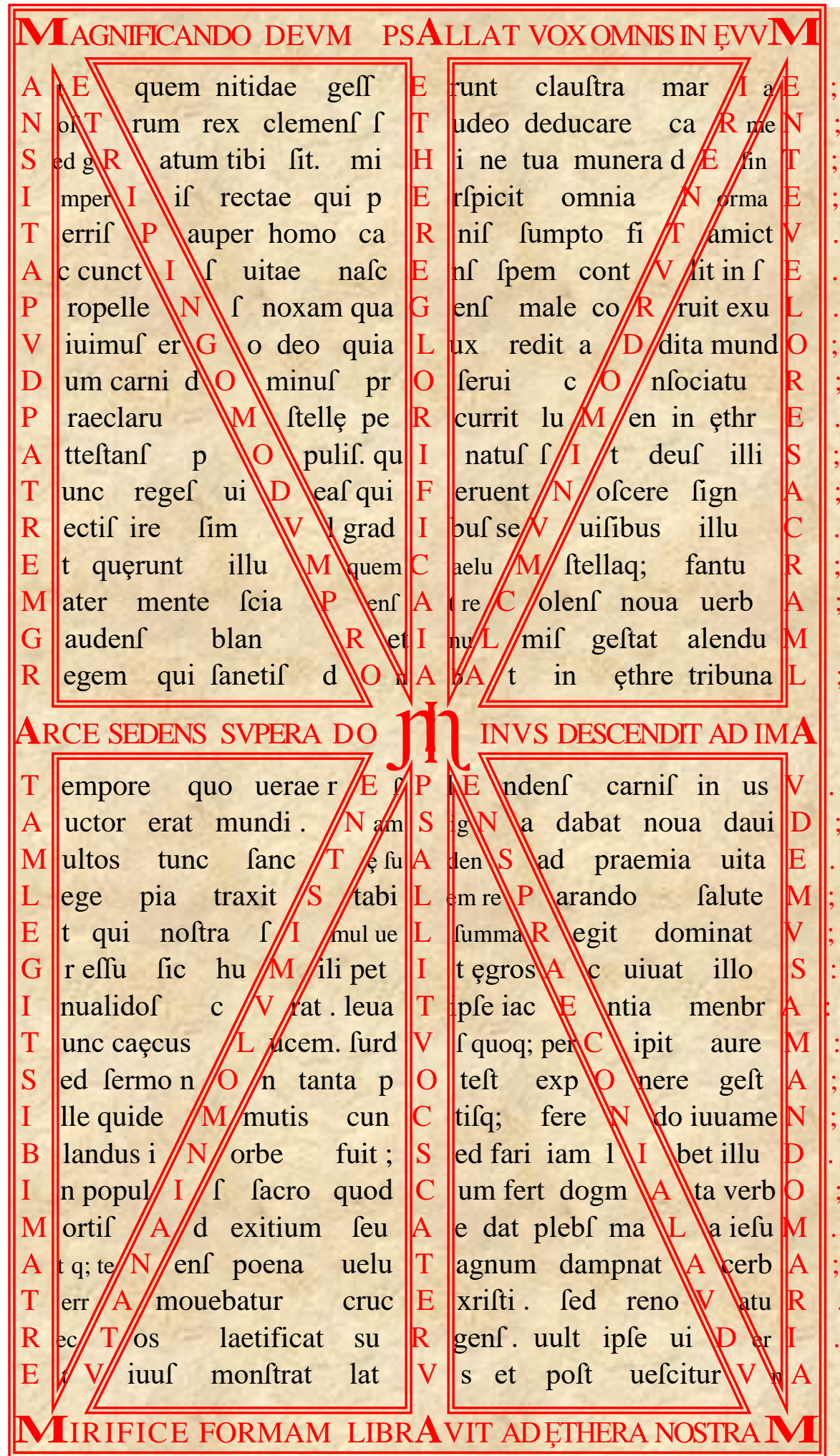

